\title{
Effects of Birth Order on Intelligence, Educational Attainment, Personality, and Risk Aversion in an Indonesian Sample
}

\section{Laura J. Botzet ${ }^{\mathrm{a}, 1}$, Julia M. Rohrer ${ }^{\mathrm{b}, \mathrm{c}, \mathrm{d}}$, and Ruben C. Arslan ${ }^{\mathrm{e}}$}

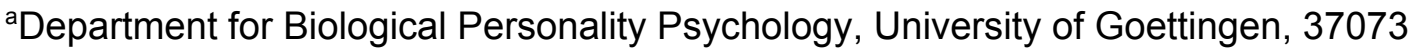

Goettingen, Germany; 'International Max Planck Research School on the Life Course (LIFE), Max Planck Institute for Human Development, 14195 Berlin, Germany; 'German Institute for Economic Research (DIW Berlin), 10117 Berlin, Germany; dDepartment of Psychology, University of Leipzig, 04109 Leipzig, Germany; ${ }^{e}$ Center for Adaptive Rationality, Max Planck Institute for Human Development, 14195 Berlin, Germany

R. C. Arslan developed the study concept. L. J. Botzet and R. C. Arslan contributed to the data analysis. All authors contributed to the interpretation of the results. L. J. Botzet drafted the manuscript and J. M. Rohrer and R. C. Arslan provided critical revisions. All authors approved the final version of the manuscript for submission.

\footnotetext{
${ }^{1}$ To whom correspondence should be addressed.

Laura J. Botzet

Institute of Psychology, Biological Personality Psychology, Goßlerstraße 14, 37073

Göttingen, Germany

E-mail: laura.botzet@stud.uni-goettingen.de

Phone: +49 17654745686
} 


\begin{abstract}
Few studies have examined birth order effects on personality in countries that are not Western, educated, industrialized, rich, and democratic (WEIRD), even though theories have generally suggested interculturally universal family dynamics as the mechanism behind birth order effects, and prominent theories such as resource dilution would even predict stronger effects in poorer countries. Here, we investigate a subset of up to 11,188 participants of the Indonesian Family Life Survey, an ongoing representative panel study, to study whether later-born siblings differ from earlier-borns in intelligence, educational attainment, personality, and risk aversion. Analyses were performed using within-family designs in mixed-effects models. In model comparisons we tested for linear and non-linear birth order effects as well as for possible interactions of birth order and sibship size. Our estimated effect sizes are consistent with the emerging account of birth order as having relatively little impact on intelligence, education, personality, and risk aversion; and they exclude recent estimates from WEIRD populations based on large sample sizes. Thus, even the small effects of birth order reported in other studies appear to be culturally specific.
\end{abstract}

Keywords: Birth Order Research, Intelligence, Educational Attainment, Personality, Risk Aversion

This article contains supporting information online at https://osf.io/8enpd/ and https://laurabotzet.github.io/birth_order_ifls/. 


\section{Introduction}

Balinese names immediately reveal a person's birth order: First-borns are called Wayan, second-borns Made, and so on. Given the everyday salience of sibling ranks, one might expect particularly pronounced birth order effects in Bali. However, previous birth order research on outcomes such as intelligence, educational attainment, and personality, has almost exclusively focused on "WEIRD" populations-populations from Western, educated, industrialized, rich, democratic countries (Heinrich, Heine, \& Norenzayan, 2010). In helping to understand human universality and variability we need to move our focus from WEIRD samples to more diverse populations (Rad, Martingano, \& Ginges, 2018).

Prominent theoretical accounts of birth order effects like resource dilution (Blake, 1981), the confluence model (Zajonc \& Marcus, 1975), and the family niche model (Sulloway, 1996) have taken no clear stance on the potential for cultural specificity. The resource dilution theory focuses on the fact that with each additional child, parental resources need to be shared among more offspring. While the first-born child can enjoy undiluted parental resources until the first sibling arrives, later-borns have to share from the very start - thus receiving less support for their intellectual development. The first-born child does not have to share parental resources for the first time of his life. Later-borns have to share the resources with older siblings - thus leading to less support for intellectual development (Blake, 1981). The confluence model argues that earlier-born children grow up in a more stimulating intellectual environment than their younger siblings because first-borns interact mostly with adults in their early development phase (Zajonc \& Marcus, 1975). The family niche model assumes that siblings compete for parental investment (Trivers, 1985) and therefore develop strategies to increase parental attention by trying to fill different niches in one family (Sulloway, 1996). These theories do not discuss potential influences by culture and thus seem to imply universal family dynamics. This suggests that birth order effects should not be specific to WEIRD populations; otherwise, we would have to conclude that 
family dynamics are less universal than assumed. In fact, explanations like resource dilution would predict even stronger birth order effects when families are large and resources are few. Hence, non-WEIRD populations would offer the most favorable conditions for detecting birth order effects due to resource dilution.

The Republic of Indonesia—the world's largest island country-is located in Southeast Asia. It is an interesting example to study birth order effects not only because it is the world's 4th most populous country and the most populous Muslim-majority country but in particular because it is home to a very diverse population that differs from WEIRD samples on which theoretical accounts of birth order effects were based. In 2015 the estimated population was about 258 million people (median age: $28.4,49.65 \%$ female), with a total fertility rate of 2.5 children per woman and a life expectancy of 68.6 years (United Nations, 2015). In $201087.18 \%$ of the total population was Muslim, $9.87 \%$ was Christian, $1.69 \%$ was Hindu, $0.72 \%$ was Buddhist, and $0.54 \%$ believed in another religion or did not believe in any religion (Badan Pusat Statistik, 2010). According to the census, in 2010 there were over 300 ethnic groups in Indonesia. $40.22 \%$ of the total population was Javanese, $15.50 \%$ was Sundanese, and $44.28 \%$ belonged to one of the other ethnic groups (each less than $5 \%$; Badan Pusat Statistik, 2010). Based on data from the UNESCO Institute of Statistics, the literacy rate in 2015 for people aged 15 years and older was $95.40 \%$ and the mean number of years in school was 7.9 (United Nations Educational, Scientific and Cultural Organization, 2015).

Recent birth order research using WEIRD samples emphasises that earlier studies were vulnerable to overfitting owing to small samples, flexible model specification, and post-hoc theorising (Rohrer, Egloff, \& Schmuckle, 2017). Although robust but small birth order effects on intelligence, educational attainment, and intellect, a facet of openness to new experiences, have recently been reported, little evidence to corroborate previously 
reported effects on other aspects of personality exists (Barclay, 2015a; Damian \& Roberts, 2015; Rohrer, Egloff \& Schmuckle, 2015; Lejarraga, Frey, Schnitzlein, \& Hertwig, 2019). Therefore, we predicted the following based on earlier studies investigating birth order effects in WEIRD samples: Intelligence, educational attainment and intellect decrease with higher birth order while birth order has no effect on extraversion, neuroticism, conscientiousness, agreeableness, and risk aversion. Given that we analyzed existing data, we did not preregister our hypotheses.

Previous research in non-WEIRD countries, which so far makes for a less comprehensive body of studies, has suffered from similar methodological problems-in particular when it comes to personality (see Table S1). A study by Calimeris and Peters (2017) based on an earlier wave of the present data idiosyncratically adjusted for educational attainment and the number of older brothers and sisters (the sum of which yields birth order) before estimating a nonlinear birth order effect on intelligence, which leaves us unable to compare its estimates to other studies. Therefore, in our study, we strove to keep our analyses straightforward and comparable to recent work on WEIRD populations, applying appropriate control for sibship size and conducting extensive robustness checks.

\section{Method}

\section{Data}

Our data comes from RAND's Indonesian Family Life Survey (IFLS), an ongoing longitudinal study with 50,148 individuals living in Indonesia. Since 1993 five waves have been administered (Frankenberg \& Thomas, 2000; Strauss, Beegle, Sikoki, Dwiyanto, Herawati, \& Witoelar, 2000; Strauss, Witoelar, Sikoki, 2016; Strauss, Witoelar, Sikoki, \& Wattie, 2009). For the first wave, a sample of households that represented about $83 \%$ of the Indonesian population was approached. In the following waves every household and all split-off households were contacted. All analyses reported in this study were run on data 
based on this representative national panel study. Hence, we had no control over the exact sample size, but with $\mathrm{N}=11,188$, it exceeds domain standards.

In each wave, women aged 15 to 49 answered questions about their pregnancy and marriage history. These questions included information about the number and order of pregnancies as well as the birth date and gender of each child. Overall 15,983 women reported 49,868 pregnancies. Marriage history allowed us to approximately infer the identity of the father. Based on this data we were able to construct full sibling order (based on the same mother and father) for 42,682 individuals.

In keeping with earlier studies we excluded families with multiple births or only children. For analyses of birth order effects, we could only include individuals who participated in the fifth wave of the IFLS. A summary of the inclusion process for the full sibling birth order is shown in Table 1.

Table 1

Data Sampling and Exclusion Criteria

\begin{tabular}{ccc}
\hline & & Number of Individuals \\
\hline Total & No multiple births & 42,682 \\
\hline \multirow{2}{*}{ Exclusion criteria } & No only children & 38,589 \\
& Still alive & 34,786 \\
& Any outcome data & 32,116 \\
\hline Interviewed for IFLS 5 & Intelligence & 11,188 \\
& Educational attainment & 5,698 \\
& Personality & 6,035 \\
& Risk aversion & 5,805 \\
\hline
\end{tabular}

Note. For the intelligence sample we only reported individuals who completed all intelligence tests. For risk aversion we report two numbers (risk A/risk B) because the sample size for the measurements differed slightly. IFLS 5: Indonesian Family Life Survey Wave 5 (2014) 
Survey materials and data are openly available on the IFLS website www.rand.org/labor/FLS/IFLS.html (Frankenberg \& Thomas, 2000; Strauss et al., 2000; Strauss et al., 2016; Strauss et al., 2009). Supplemental material can be found on the Open Science Framework https://osf.io/8enpd/. All our analyses and code are documented on our website https://laurabotzet.github.io/birth_order ifls/.

\section{Outcomes}

We included intelligence, educational attainment, personality and risk aversion as outcomes in our main analyses. Additional analyses (results reported on the supplementary website) included income, self employment, working category (e.g., unpaid family worker), working sector, and smoking behavior as outcomes. Continuous outcomes were z-standardized $(M=0, S D=1)$ to make effect sizes easier to compare. For a detailed description of all outcomes see Strauss et al. (2016).

Intelligence. In the fifth wave of IFLS five intelligence subtests were conducted. All respondents aged 15 or older were asked to take part in these tests. a) They answered a shortened version of a Raven's matrices test that consisted of eight items. For each item, respondents were asked to identify the missing element out of six possible elements to complete a pattern. b) They were asked to count backwards from 100 in steps of 7s. c) They were given a delayed word recall test. Participants heard a list of 10 nouns and had to recall as many words as possible four to five minutes later. d) They were given an adaptive number series test in which each participant answered six out of 15 items. Each item showed a pattern of numbers with one missing value. Participants had to name the missing number (e.g., "7 - 8 - ? - 10"). The first three items were given to all participants. Based on the accuracy of the first three responses a subsequent set of three items was chosen. A Rasch scoring model was used to identify a person's ability for a given set of response 
patterns with varying difficulties. Thus a composite score was calculated for each participant (Strauss et al., 2016). e) All respondents aged 15 to 59 participated in a math test. Each respondent answered five multiple choice questions measuring mathematical abilities (three mathematical calculations and two math text problems).

Years of education. Participants reported the highest educational level they had attended (elementary, junior high, senior high, university) and the highest grade they completed at this educational level. Based on these items we were able to reconstruct years of education.

Personality. Personality was assessed with the Big Five Index 15 (BFI 15) for all respondents aged 15 or older. The BFI 15 is based on the Big Five Inventory-SOEP (Schupp \& Gerlitz, 2008), which in turn is a very short version of the Big Five Inventory and precludes examining single personality facets (e.g., intellect). It was translated into Indonesian. All 15 items started with the phrase "I see myself as someone who ...". Three items were asked for each of the Big Five personality dimensions: extraversion (e.g., "... is talkative.”), neuroticism (e.g., “... worries a lot.”), conscientiousness (e.g., “... does a thorough job."), agreeableness (e.g., "... is considerate and kind to almost everyone.”), and openness (e.g. " $\ldots$ is original, comes up with new ideas."). Participants expressed their agreement on a 5-point Likert scale (from 1 = "Disagree strongly" to 5 = "Agree strongly").

Risk aversion. Risk aversion was assessed with an adaptive hypothetical lottery choice task for all respondents aged 15 or older. Analyses of the Mexican Family Life Survey had suggested that hypothetical lotteries yield similar results to lotteries that are paid out (Hamoudi, 2006). Two different sets of questions, A and B, were asked (randomized order across participants). The sets differed in the amount of the payoffs and the variance of their expected payoffs. Set B's certain payoffs were higher than A's. The uncertain payoffs in Set 
B had higher coefficients of variation than those in A, reflecting a higher risk-reward ratio (for a more detailed description see $\mathrm{Ng}, 2013)$. Many participants gave inconsistent responses across the two tasks and current research suggests that lottery tasks may be poor measures of individual differences in risk preferences compared to self-reports (Frey, Pedroni, Mata, Rieskamp, \& Hertwig, 2017).

Additional outcomes. To further investigate the effects of birth order on additional outcomes we included income, self employment, sector of work and smoking behavior. Analyses and results can be found on the supplementary website.

\section{Analysis}

Birth order and sibship size were calculated for full sibships (same father and mother) based on the maternal reports of pregnancy and marriage history of all women aged 15-49 who participated in an IFLS wave. In all models, we adjusted for the number of siblings, self-reported gender, a third-order polynomial for age, and a family random effect to account for dependencies within sibships. We then tested for a linear birth order effect, for nonlinear effects (by testing categorical effects of birth order 1 to 5 and over 5 ), and for potential interactions with number of siblings, and went on to iteratively compare models to see whether each model improved upon the preceding one. Additionally, we reported estimates and confidence intervals of the birth order effects to further examine the influence of birth order on the outcomes and compare effect sizes to the existing literature.

We performed additional robustness analyses based on maternal sibships and maternal pregnancy order (including, e.g., stillbirths) and we tested the effect of excluding all individuals in sibships bigger than five. Furthermore, we repeated all analyses after multiple imputation (for details see section about handling missing data). We state where results 
changed depending on the analysis approach and report all robustness analyses on the website.

We reported the results of our model comparisons for each outcome based on full sibling order. Because of the number of outcomes and owing to calls for more stringent significance cutoffs in empirical science, we set the significance threshold to .005 (Benjamin et al., 2017). We summarise results here briefly, and report them in full online.

All analyses were conducted in R, version 3.3.3 (R Core Team, 2013). We conducted within-family analyses by running mixed effects models using the Ime4 package Version 1.1-12 (Bates, Mächler, Bolker, \& Walker, 2015).

\section{Handling missing data}

As in other large panel studies, the IFLS had non-ignorable missing data. Some questions were only answered by a subset of participants (depending on age), some participants were absent for one of the waves, some mothers did not fill out the pregnancy questionnaire which we used to ascertain birth order, and some missing data were due to panel mortality. To impute birth order for individuals whose mothers had not filled out the pregnancy questionnaire, we computed variables which we called "naive birth order" and "naive sibling count." This was simply the order according to birth year by people reporting the same mother. Pre-imputation analyses showed high agreement between the naive birth order and the full sibling order ( $r=.91,95 \% \mathrm{Cl}:[.90, .91])$, although systematic missing data are likely.

Following Grund, Lüdtke and Robitzsch (2017), we performed multiple imputation for multilevel data. We included the identity of the mother as a grouping variable and imputed variables which were correlated $r>.1$ (see Table S2 in the supplemental material for a list of all variables included). We used the R packages MICE package version 2.46.0 (Buuren \& Groothuis-Oudshoorn, 2010) and pan package version 1.4 (Schäfer, 1997) to impute the 
data. We generated 100 imputed datasets, ran all models 100 times, and aggregated estimates and standard errors using the mitml package (Grund, Robitzsch, \& Lüdtke, 2018). To evaluate the quality of imputations, we examined intraclass correlations, density plots, and trace plots. Details are reported online.

\section{Results}

\section{Sample analysis}

We found that our main sample of people for whom birth order could be computed systematically differed from those for whom the required information was missing. Our main sample was 25 years younger and the percentage of female individuals was 2 percentage points higher. The main sample was also more intelligent $(d=0.82)$ and had more years of educational attainment $(d=0.82)$; it was more extraverted $(d=0.09)$, more neurotic $(d=0.11)$, less conscientious $(d=-0.19)$, and less agreeable $(d=-0.13)$; it also scored higher on openness $(d=0.23)$ and showed differences in risk aversion with inconsistent signs across the two measures (decreased risk aversion for risk A: $d=-0.10$; increased for risk B: $d=0.08)$. These differences were all significant (all $p s<.001)$.

Intelligence g-factor. Based on the results of the Raven's matrices test, the math test, the backwards counting task, the delayed word recall, and the adaptive number series from all individuals who took part in wave 5 of the IFLS, we computed a $g$ factor of intelligence. Based on a sample of participants who completed all five of the intelligence tests in wave 5 $(n=27,526)$ we ran a confirmatory factor analysis expecting one factor. The $g$ factor explained $42 \%$ of variance in the Raven's matrices test, $25 \%$ of variance in the math test, $20 \%$ of variance in the backwards counting task, $23 \%$ of variance in the delayed word recall, and $40 \%$ of variance in the adaptive number series. 
Descriptive statistics. Table 2 shows raw means, standard deviations, and a correlation matrix for age, gender, intelligence, educational attainment, extraversion, neuroticism, conscientiousness, agreeableness, and both risk aversion measurements based on our main sample with birth order information $(n=11,188)$. The correlation between age and intelligence $(r=-.10)$ and age and personality (extraversion: $r=.00$, neuroticism: $r=-.13$, conscientiousness: $r=.24$, agreeableness: $r=.10$ and openness: $r=.00$ ) were consistent with trends found in WEIRD samples (Nisbett, Aronson, Blair, Dickensen, Flynn, Halpern \& Turkheimer, 2012; Roberts, Walton, \& Viechtbauer, 2006). Being male was negatively correlated with extraversion $(r=-.13)$ and risk aversion (risk A: $r=-.13$; risk B: $r=-.12$ ). Intelligence was positively correlated with extraversion $(r=.06)$, neuroticism $(r=.05)$, and openness $(r=.08)$, and slightly negatively correlated with conscientiousness $(r=-.03)$ and agreeableness $(r=-.04)$. No consistent correlation pattern was visible for intelligence and risk aversion (risk A: $r=-.15$; risk B: $r=.05$ ). The correlations between the five dimensions of personality matched those found in a German sample (Hahn, Gottschling, \& Spinath, 2012) with positive correlations between all personality dimensions except for neuroticism. The two risk aversion tasks correlated moderately with each other $(r=.30)$. 
Table 2

Means, Standard Deviations, and Correlation Matrix for Age, Gender, Intelligence,

Educational Attainment, Personality and Risk Aversion.

\begin{tabular}{|c|c|c|c|c|c|c|c|c|c|c|c|c|}
\hline Measure & Mean & SD & (1) & (2) & (3) & (4) & (5) & (6) & (7) & (8) & (9) & (10) \\
\hline (1) Age & 13.75 & 10.83 & & & & & & & & & & \\
\hline $\begin{array}{l}\text { (2) Gender: } \\
\text { Female }\end{array}$ & .51 & & -.03 & & & & & & & & & \\
\hline $\begin{array}{c}\text { (3) } \\
\text { Intelligence }\end{array}$ & 0.45 & 0.68 & -.10 & -.01 & & & & & & & & \\
\hline $\begin{array}{l}\text { (4) Years of } \\
\text { education }\end{array}$ & 11.40 & 3.49 & .24 & -.05 & .35 & & & & & & & \\
\hline (5) $\mathrm{E}$ & 3.49 & 0.68 & .00 & -.13 & .06 & .07 & & & & & & \\
\hline (6) $\mathrm{N}$ & 2.63 & 0.50 & -.13 & .02 & .05 & -.01 & -.12 & & & & & \\
\hline (7) C & 3.73 & 0.58 & .24 & .02 & -.03 & .10 & .07 & -.19 & & & & \\
\hline (8) $\mathrm{A}$ & 3.85 & 0.51 & .03 & .03 & -.04 & .03 & .07 & -.17 & .32 & & & \\
\hline (9) $\mathrm{O}$ & 3.82 & 0.60 & .08 & .08 & .08 & .15 & .17 & -.17 & .27 & .23 & & \\
\hline (10) Risk A & 3.29 & 1.45 & -.15 & -.13 & -.15 & -.19 & -.19 & -.02 & -.04 & -.02 & -.08 & \\
\hline (11) Risk B & 4.29 & 1.31 & .05 & -.12 & .05 & -.02 & -.02 & -.01 & .02 & -.01 & -.03 & .30 \\
\hline
\end{tabular}

Notes. Data is based on the main sample $(n=11,188)$. E: Extraversion, $\mathrm{N}$ : Neuroticism,

C: Conscientiousness, A: Agreeableness, O: Openness. 


\section{Birth Order Effects}

Analyses showed no significant improvement of model fit when including birth order as a predictor for intelligence, personality, and risk aversion (all $p s>.02$ ). We found evidence for a nonlinear effect of birth order on educational attainment $\left(X^{2}(4, N=6035)=21.48, p<.001\right)$. A closer look at the categorical effect showed a checkmark-shaped pattern, indicating less educational attainment for the second-born compared to the first-born (estimation of effect: $-0.06,95 \% \mathrm{Cl}:[-.10,-.01])$; the same amount of educational attainment for the third-born compared to the first-born (estimation of effect: $0.02,[-.04,0.07])$; and more educational attainment for fourth- (estimation of effect: $0.09[0.02,0.15])$ or fifth-borns (estimation of effect: $0.14[0.05,0.22])$. Differences between fifth- and later-borns in educational attainment level were not significant (estimation of effect: $0.08[-.01,0.16])$

Including the interaction of sibship size and birth order as a predictor did not improve any of the models significantly $(p>0.06)$. In Figure 1 , we show the interaction of sibship size and birth order (adjusted for gender, age and family). Additional analyses showed no significant effects of birth order on income, self employment, working category, working sector, and smoking behavior (all analyses online).

Figure 2 shows linear effects of birth order and sibship size on all outcomes, with effect sizes based on z-standardized outcomes. The estimate for the linear birth order effect on years of education was $.015[.004, .03]$. The dotted line shows an estimate of birth order effects on intelligence and intellect as reported in Rohrer et al. (2015). Not only do the confidence intervals of most of our estimates include zero, they also exclude the estimates from WEIRD populations. 
a.

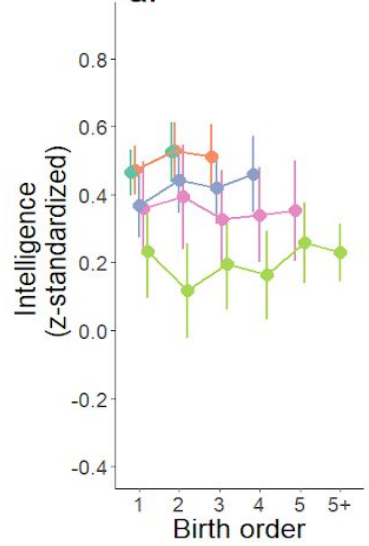

d.

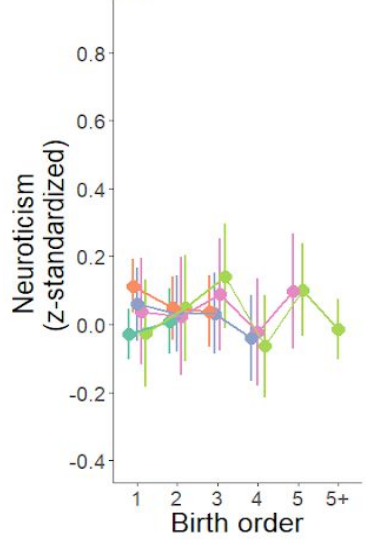

g.

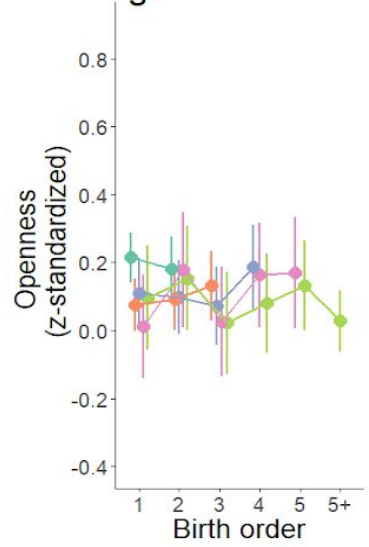

b.

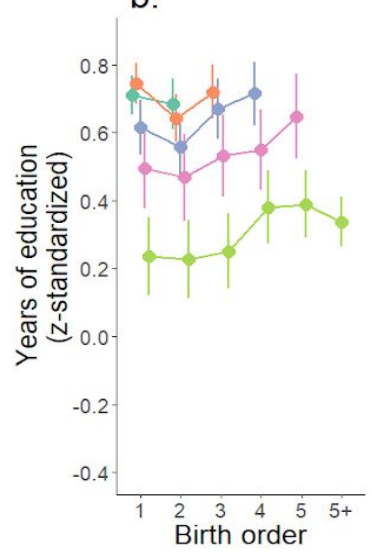

e.
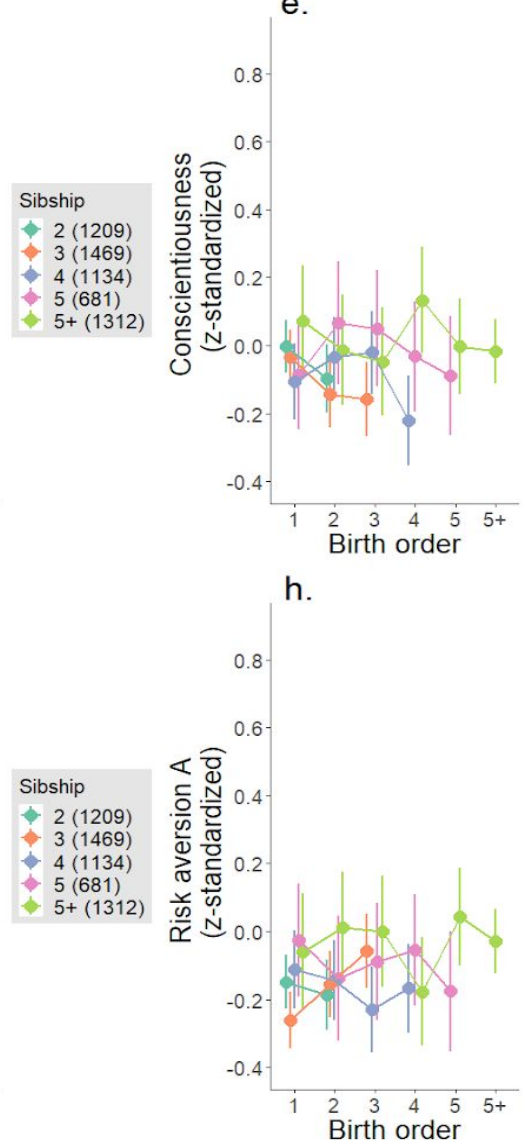

h.

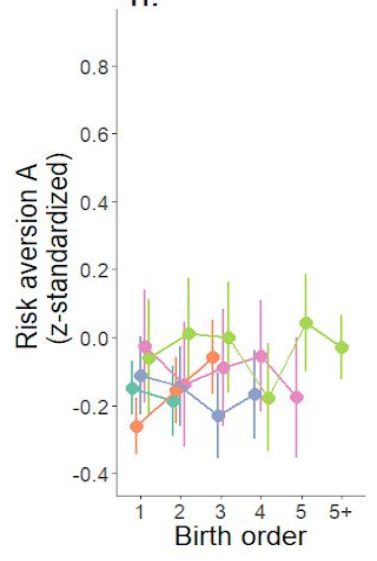

c.
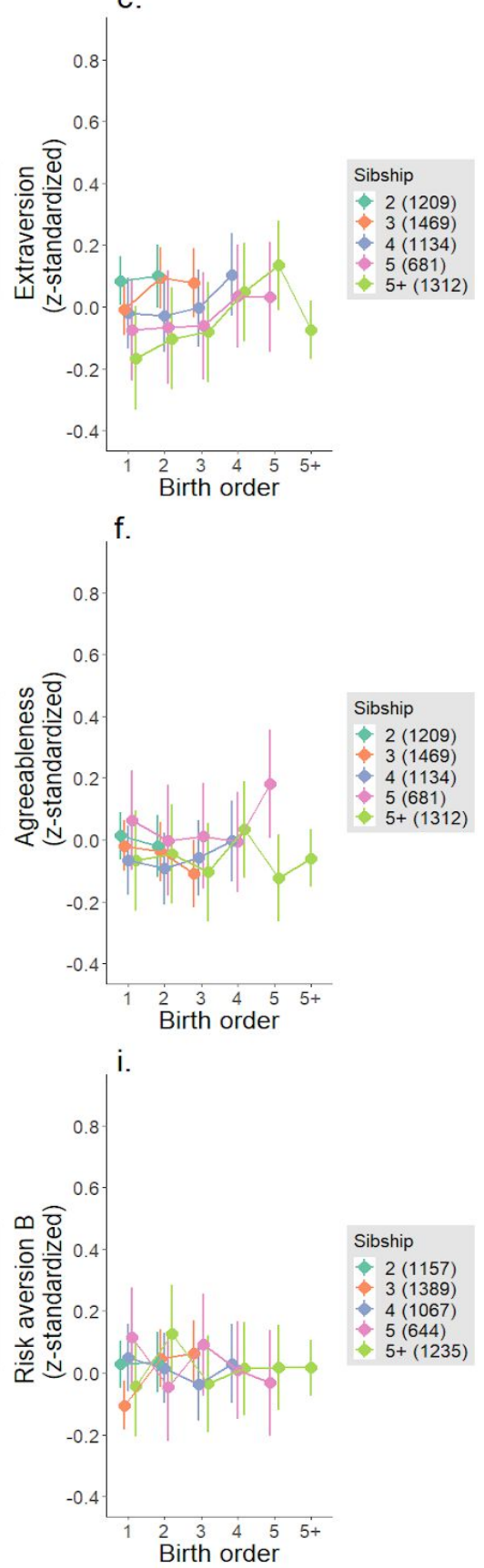

Figure 1. Interaction effects of sibship size and birth order position on intelligence, personality, and risk aversion. Predicted mean scores and 95\% confidence intervals from linear mixed effects models with sibship size, birth order, gender, and age as fixed effects and maternal identity as random effect are displayed for (a.) intelligence, (b.) educational attainment, (c.) extraversion, (d.) neuroticism, (e.) conscientiousness, (f.) agreeableness, (g.) openness, and (h. $-\mathrm{i}$.) risk aversion. All outcome measurements are z-standardized based on the full sample. Numbers in parentheses show sample size. 


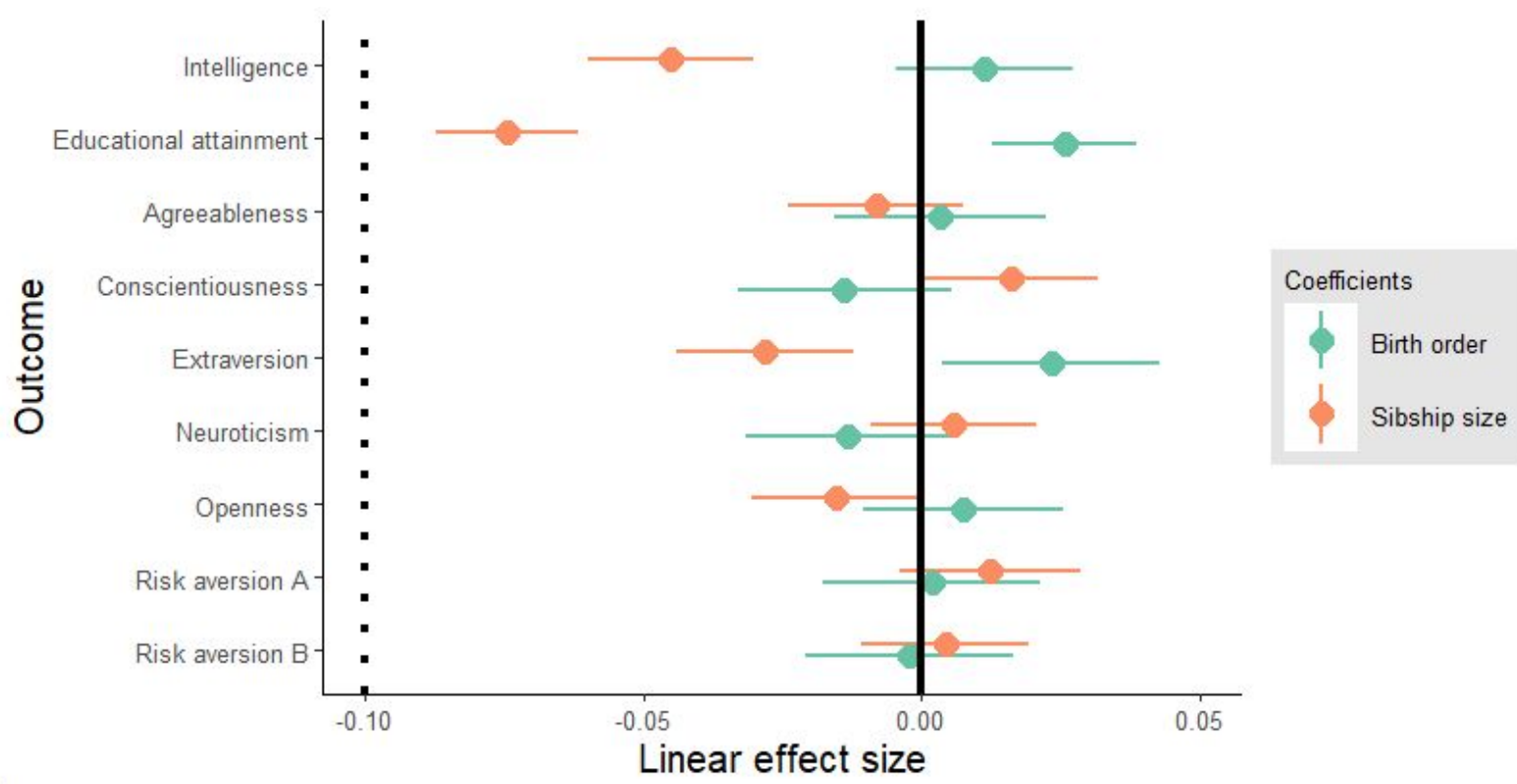

Figure 2. Effect size estimates in standard deviations for linear effects of birth order and sibship size. Effect size and 95\% confidence intervals from linear mixed effects models with sibship size, birth order, gender, and age as fixed effects and maternal identity as random effect are shown. The dotted line shows an estimate of birth order effects on intelligence and intellect from a Western sample (Rohrer et al., 2015).

\section{Discussion}

We found no birth order effects on intelligence, agreeableness, conscientiousness, extraversion, neuroticism, openness, or risk aversion, regardless of whether we included birth order as a continuous or categorical predictor, or whether we considered its interaction with sibship size. Model comparisons supported a robust but small nonlinear effect of birth order on educational attainment in form of a checkmark-shaped pattern.

Our results were consistent with null effects on agreeableness, conscientiousness, extraversion, neuroticism, and risk aversion found in WEIRD populations (Damian \& Roberts, 2015; Lejarraga et al., 2019; Rohrer et al., 2015). Yet, we found no effect of birth order on intelligence nor openness in contrast to the small negative estimates reported for WEIRD populations (Barclay, 2015b; Damian \& Roberts, 2015; Rohrer et al., 2015; Rohrer et al., 2017). Additionally, the nonlinear effect of birth order on educational attainment was reversed compared to earlier studies. Based on WEIRD samples higher birth order is related 
to lower educational attainment (Black, Devereux, \& Salvanes; 2005; Booth \& Kee, 2009; Härkönen, 2013; Kristensen \& Bjerkedal, 2010), even in fully adopted sibling groups (Barclay, 2015). However, in this Indonesian sample higher birth order is related to higher educational attainment.

Thus, our results are inconsistent with predictions from Blake's resource dilution model (Blake, 1981), Zajonc's confluence model (Zajonc \& Markus, 1975), and Sulloway's sibling roles (Sulloway, 1996). These theories made no allowance for fundamental cultural differences in family dynamics. Given that Indonesia is a poorer country with larger families than most previously studied countries, resource dilution would have predicted larger effects on average. Observed effects fell short of initial predictions from theories on family dynamics that were based on the largest, best evidence available in the WEIRD world. It is therefore appropriate to look for other explanations. Perhaps birth order influences the social and parental expectations for first-born children in some countries, through remnants of Western cultural norms like primogeniture, or through policies such as parental leave (Barclay, 2015b). Children's traits may then adapt due to external influences on their educational and occupational choices, such as a father expecting a first-born to take over the family business (Barclay, Hällsten, \& Myrskylä, 2017). Such an indirect effect would be consistent with the generally observed small average birth order effects, as well as with the absence of those effects in a culturally different country.

Further support for this theory is provided by the pattern of educational attainment based on birth order. The results for educational attainment reported in this study are consistent with results from other in non-WEIRD samples: educational attainment increases with birth-order in Brazil (Emerson \& Souza, 2008) and in the Philippines (Ejrnæs \& Pörtner, 2004). In Bangladesh, Park and Chung (2012) found that first- and second-borns with additional younger siblings receive less educational attainment than only children or children in families with a sibship size of two. Interestingly, Dayioğlu, Kirdar, and Tansel (2009) found 
a parabolic pattern for urban Turkey: first-borns and last-borns received more educational attainment than middle-borns. One explanation for the effect of birth order on educational attainment in non-WEIRD countries could be child labor. Because older siblings have the chance to earn higher wages than their younger siblings they have to work earlier than their younger siblings and do not attend school for very long. When younger siblings reach the same age as their older siblings the need to work to support their family is not as high, especially for male last-borns (Emerson \& Souza, 2008).

In our data, we found no evidence for birth order effects on various outcomes related to type of employment and work sector, corroborating the emerging narrative that birth order is generally not a very important predictor of life outcomes.

From a broader perspective, our study highlights the need to go beyond Western countries to test whether theoretical accounts implicitly or explicitly assumed to hold universally actually do operate across cultures. Robust discrepancies between findings from different cultural backgrounds can inform theory and elucidate mechanisms that drive effects—but only if researchers do not limit themselves to WEIRD populations. 


\section{Acknowledgements}

We are grateful to the RAND corporation that conducts the Indonesian Family Life Survey and to the survey participants. Additionally, we would like to thank Deb Ain for her careful scientific editing. All remaining errors are ours. 


\section{References}

Badan Pusat Statistik. (2010). "Kewarganegaraan, suku bangsa, agama, dan bahasa sehari-hari penduduk indonesia" [Citizenship, racial, religious and everyday linguistic of the Indonesian people]. Retrieved from http://sp2010.bps.go.id/files/ebook/kewarganegaraan\%20penduduk\%20indonesia/index. html

Bates, D., Mächler, M., Bolker, B., \& Walker, S. (2015). Fitting linear mixed-effects models using Ime4. Journal of Statistical Software, 67(1), 1-48. doi:10.18637/jss.v067.i01

Barclay, K. J. (2015a). A within-family analysis of birth order and intelligence using population conscription data on Swedish men. Intelligence, 49, 134-143. doi:10.1016/j.intell.2014.12.007

Barclay, K. J. (2015a). Birth order and educational attainment: Evidence from fully adopted sibling groups. Intelligence, 48, 109-122. doi:10.1016/j.intell.2014.10.009

Barclay, K., Hällsten, M., \& Myrskylä, M. (2017). Birth order and college major in Sweden. Social Forces, 96(2), 629-660. doi:10.1093/sf/sox069

Benjamin, D. J., Berger, J. O., Johannesson, M., Nosek, B. A., Wagenmakers, E.-J., Berk, R., ... Johnson, V. E. (2017). Redefine statistical significance. Nature Human Behaviour, 2(1), 6-10. doi:10.1038/s41562-017-0189-z

Black, S. E., Devereux, P. J., \& Salvanes, K. G. (2005). The more the merrier? The effect of family size and birth order on children's education. The Quarterly Journal of Economics, 120(2), 669-700. doi:10.1093/qje/120.2.669

Blake, J. (1981). Family size and the quality of children. Demography, 18(4), 421-442. doi: $10.2307 / 2060941$

Booth, A. L., \& Kee, H. J. (2009). Birth order matters: the effect of family size and birth order on educational attainment. Journal of Population Economics, 22(2), 367-397. doi:10.1007/s00148-007-0181-4 
Buuren, S. V., \& Groothuis-Oudshoorn, K. (2010). mice: Multivariate imputation by chained equations in R. Journal of statistical software, 1-68. doi: 10.18637/jss.v045.i03

Calimeris, L., \& Peters, C. (2017). Food for thought: The birth-order effect and resource allocation in Indonesia. Applied Economics, 49(54), 5523-5534. doi:10.1080/00036846.2017.1311005

Damian, R. I., \& Roberts, B. W. (2015). The associations of birth order with personality and intelligence in a representative sample of U.S. high school students. Journal of Research in Personality, 58, 96-105. doi:10.1016/j.jrp.2015.05.005

Dayioğlu, M., Kirdar, M. G., \& Tansel, A. (2009). Impact of sibship size, birth order and sex composition on school enrolment in urban Turkey. Oxford Bulletin of Economics and Statistics, 71(3), 399-426. doi:10.1111/j.1468-0084.2008.00540.x

Ejrnæs, M., \& Pörtner, C. C. (2004). Birth order and the intrahousehold allocation of time and education. Review of Economics and Statistics, 86(4), 1008-1019. doi:10.1162/0034653043125176

Emerson, P. M., \& Souza, A. P. (2008). Birth order, child labor, and school attendance in Brazil. World Development, 36(9), 1647-1664. doi:10.1016/j.worlddev.2007.09.004 Frankenberg, E., \& Thomas, D. (2000). The Indonesia Family Life Survey (IFLS): Study design and results from waves 1 and 2. Santa Monica, CA: RAND. DRU-2238/1-NIA/NICHD

Frey, R., Pedroni, A., Mata, R., Rieskamp, J., \& Hertwig, R. (2017). Risk preference shares the psychometric structure of major psychological traits. Science advances, 3(10), e1701381. doi:10.1126/sciadv.1701381

Grund, S., Lüdtke, O., \& Robitzsch, A. (2017). Multiple imputation of missing data for multilevel models: Simulations and recommendations. Organizational Research Methods, 21(1), 111-149. doi:10.1177/1094428117703686 
Grund, S., Robitzsch, A., \& Lüdtke, O. (2018). mitml: Tools for Multiple Imputation in Multilevel Modeling. R package version 0.3-6. Retrieved from https://CRAN.R-project.org/package=mitml

Härkönen, J. (2013). Birth order effects on educational attainment and educational transitions in West Germany. European sociological review, 30(2), 166-179. doi:10.1093/esr/jct027

Hahn, E., Gottschling, J., \& Spinath, F. M. (2012). Short measurements of personality—Validity and reliability of the GSOEP Big Five Inventory (BFI-S). Journal of Research in Personality, 46(3), 355-359. doi:10.1016/j.jrp.2012.03.008

Hamoudi, A. (2006). Risk preferences in households and families. Unpublished Manuscript. Retrieved from https://www.cgdev.org/doc/events/02.06.07/hamoudiJMP.pdf Heinrich, J., Heine, S. J., \& Norenzayan, A. (2010). The weirdest people in the world? Behavioral and Brain Sciences, 33(2-3), 61-83. doi:10.1017/S0140525X0999152X Kristensen, P., \& Bjerkedal, T. (2010). Educational attainment of 25 year old Norwegians according to birth order and gender. Intelligence, 38(1), 123-136. doi: 10.1016/j.intell.2009.08.003

Lejarraga, T., Frey, R., Schnitzlein, D. D., \& Hertwig, R. (2019). No effect of birth order on adult risk taking. Proceedings of the National Academy of Sciences, 116(13), 6019-6024. doi:10.1073/pnas.1814153116

$\mathrm{Ng}$, J. (2013). Elicited risk and time preferences: The role of demographics, cognition, and interviewers. Unpublished Manuscript. Retrieved from http://static1.1.sqspcdn.com/static/f/884336/20238159/1347396545633/ng_dev_seminar 9-10.pdf?token=lyKlyXB8PkRIMZdh0sSqSLzFtcg\%3D

Nisbett, R. E., Aronson, J., Blair, C., Dickens, W., Flynn, J., Halpern, D. F., \& Turkheimer, E. (2012). Intelligence: New findings and theoretical developments. American Psychologist, 67(2), 130-159. doi:10.1037/a0026699 
Park, C., \& Chung, W. (2012). Sibship size, birth order, and children's education in developing countries: Evidence from Bangladesh. Hitotsubashi Journal of Economics, 1-23. doi:10.15057/23151

R Core Team. (2013). R: A language and environment for statistical computing. Vienna, Austria: R Foundation for Statistical Computing. Retrieved from http://www.R-project.org/

Rad, M. S., Martingano, A. J., \& Ginges, J. (2018). Toward a psychology of Homo sapiens: Making psychological science more representative of the human population. Proceedings of the National Academy of Sciences, 115(45), 11401-11405. doi:10.1073/pnas.1721165115

Roberts, B. W., Walton, K. E., \& Viechtbauer, W. (2006). Patterns of mean-level change in personality traits across the life course: A meta-analysis of longitudinal studies. Psychological Bulletin, 132(1), 1. doi:10.1037/0033-2909.132.1.1

Rohrer, J. M., Egloff, B., \& Schmukle, S. C. (2015). Examining the effects of birth order on personality. Proceedings of the National Academy of Sciences, 112(46), 14224-14229. doi:10.1073/pnas.1506451112

Rohrer, J. M., Egloff, B., \& Schmukle, S. C. (2017). Probing birth-order effects on narrow traits using specification-curve analysis. Psychological Science, 28(12), 1821-1832. doi:10.1177/0956797617723726

Schafer, J. L. (1997). Pan: Multiple imputation for multivariate panel or clustered data. Retrieved from https://CRAN.R-project.org/package=pan

Schupp, J., \& Gerlitz, J.-Y. (2008). Big Five Inventory-SOEP (BFI-S). In Zusammenstellung sozialwissenschaftlicher Items und Skalen. ZIS Version (Vol. 12). doi:10.6102/zis54

Strauss, J., Beegle, K., Sikoki, B., Dwiyanto, A., Herawati, Y., Witoelar, F. (2000). The Third Wave of the Indonesia Family Life Survey (IFLS): Overview and Field Report. WR-144/1-NIA/NICHD. 
Strauss, J., Witoelar, F., \& Sikoki, B. (2016). The Fifth Wave of the Indonesia Family Life Survey: Overview and Field Report. WR-1143/1-NIA/NICHD

Strauss, J., Witoelar, F., Sikoki, B., Wattie, A. M. (2009). The Fourth Wave of the Indonesian Family Life Survey (IFLS4): Overview and Field Report. WR-675/1-NIA/NICHD

Sulloway, F. J. (1996). Born to rebel: Birth order, family dynamics, and creative lives (Vol. xviii). New York, NY: Pantheon Books.

Trivers, R. (1985). Social evolution. San Francisco, CA: Benjamin-Cummings

United Nations Educational, Scientific and Cultural Organization. (2015). UNESCO Institute for Statistics: UNESCO Institute for Statistics. Retrieved from http://sp2010.bps.go.id/files/ebook/kewarganegaraan\%20penduduk\%20indonesia/index. html

United Nations, Department of Economic and Social Affairs, \& Division, P. (2015). World Population Prospects: The 2015 Revision, Volume II: Demographic Profiles

Zajonc, R. B., \& Markus, G. B. (1975). Birth order and intellectual development. Psychological Review, 82(1), 74-88. doi:10.1037/h0076229 